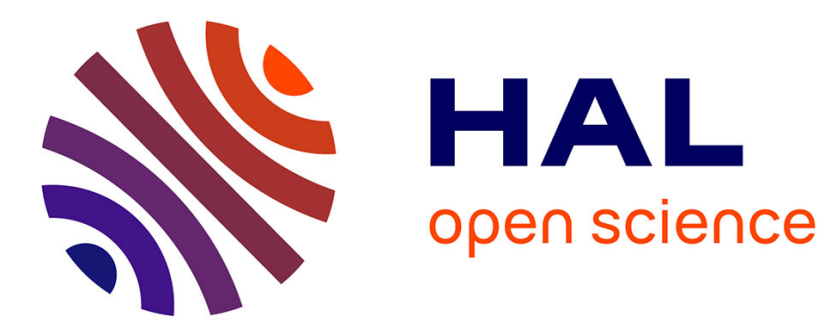

\title{
Mechanical Behavior of Nanocomposite Aerogels
}

Thierry Woignier, Juan Primera, Adil Alaoui, Sylvie Calas-Etienne

\section{To cite this version:}

Thierry Woignier, Juan Primera, Adil Alaoui, Sylvie Calas-Etienne. Mechanical Behavior of Nanocomposite Aerogels. Lisa Klein; Andrei Jitianu; Mario Aparicio. Handbook of Sol-Gel Science and Technology: Processing, Characterization and Applications, , pp.3375 - 3392, 2018, 978-3-319-32099-1. 10.1007/978-3-319-32101-1_91. hal-01929809

\section{HAL Id: hal-01929809 \\ https://hal-amu.archives-ouvertes.fr/hal-01929809}

Submitted on 21 Nov 2018

HAL is a multi-disciplinary open access archive for the deposit and dissemination of scientific research documents, whether they are published or not. The documents may come from teaching and research institutions in France or abroad, or from public or private research centers.
L'archive ouverte pluridisciplinaire HAL, est destinée au dépôt et à la diffusion de documents scientifiques de niveau recherche, publiés ou non, émanant des établissements d'enseignement et de recherche français ou étrangers, des laboratoires publics ou privés. 


\title{
Mechanical Behavior of Nanocomposite Aerogels
}

\author{
Thierry Woignier, Juan Primera, Adil Alaoui, and \\ Sylvie Calas-Etienne
}

\begin{abstract}
Aerogels are generally described in terms of brittle and elastic materials, like glasses or ceramics with poor and not predictable mechanical properties. We propose the synthesis of a nanocomposite aerogels with improved mechanical
\end{abstract}

\footnotetext{
T. Woignier $(\bowtie)$

IMBE, CNRS, IRD, Aix Marseille Université, Avignon Université, Marseille, France

IRD - Campus Agro Environnemental Caraïbes, Le Lamentin, Martinique, France

e-mail: thierry.woignier@univ-montp2.fr

J. Primera

Departamento de Fisica, FEC, LUZ, Maracaibo, Venezuela

Escuela Superior Politécnica del Litoral (ESPOL) Facultad de Ciencias Naturales y Matemáticas, Departamento de Física, Campus Gustavo Galindo, Guayaquil, Ecuador
}
A. Alaoui
Faculté des Sciences et Techniques de Tanger, Tanger, Morocco
S. Calas-Etienne
Laboratoire Charles Coulomb, Université Montpellier 2, Montpellier Cedex 5, France 
properties by addition of silica particles (aerosil; 20-100 nm) in the monomer solution. The elastic modulus and rupture strength increase, stiffening and strengthening the structure by a factor 5-8. The toughness, the critical flaw size, and the fracture energy increase also versus the silica particle concentration. Moreover, the mechanical strength distribution and the Weibull modulus, m, characterizing the statistical nature of flaw size in brittle materials show a more homogeneous flaw size distribution. Pores are considered as integral part of flaws, and small angle $\mathrm{X}$-ray scattering shows that the usual fractal structure observed in aerogel disappears with the silica particle addition. The fractal structure in aerogel is characteristic of a large pore size distribution, but also of a large flaw size distribution.

If nanocomposites behave as brittle material under a tension stress, they exhibit a different response when the structure is submitted to a compression: densification and plastic hardening. These opposite behaviors (brittle and plastic) are surprisingly related to the same kinds of gel features: pore volume, silanol content, and the pore size distribution. Because of improved mechanical properties, these nanocomposites aerogels could be used as host matrices for the synthesis of glass ceramics, doped glasses, and composites.

\section{Introduction}

The mechanical behavior of common glasses is now well known; glasses are brittle and show a pure elastic behavior. General agreement is that porous glasses also exhibit a brittle and elastic behavior, but their mechanical characteristics (strength, elastic constant, toughness, fracture energy) are lower due to the pore volume (Gibson and Ashby 1988; Rice 1998). Porous glasses can originate from different processes, corrosion, microphase separation (Elmer 1992), and foaming inside the melt (Pernot et al. 1983). In the last decades, a new kind of "like porous glasses" (xerogels and aerogels) has been synthesized by sol-gel process (Brinker and Scherer 1990). In the family of gels, aerogels have known an increasing interest in different fields from the fundamental research in physics to the applications as specific materials (Schaeffer and Keefer 1986; Courtens et al. 1987; Brinker and Scherer 1990; Emmerling and Fricke 1997; Fricke 1992; Aegerter 2011). Their properties of interest include low thermal conductivity, low density, thermal insulation, catalysts, and doped materials.

The mechanical behavior of gels has been attracting the attention of engineers and researchers because of practical and theoretical considerations related to the porous media. The study of heterogeneous material fracture towards a better understanding of damage mechanisms has received a lot of attention in the physics community. In order to predict the failure of foamed materials, fracture can be described as a clustering of microcracks (Deschanel et al. 2009). In the literature, aerogels are generally described as elastic and brittle materials (Dumas et al. 1990; Woignier et al. 1988; Scherer 1992; Alaoui et al. 2000). The general agreement on their 
mechanical behavior is that the silica aerogels are brittle materials and the stress-strain relation evolves toward a "catastrophic" fracture. Consequently, the theory of linear elastic fracture mechanics could be applied on aerogels to measure the toughness and defect size (Zarzycki 1988; Scherer 1992; Alaoui et al. 2000). In brittle materials, the strength is strongly dependent on the presence of flaws, which act as stress concentrators (Griffith 1920), and the most relevant feature of brittle materials is their toughness. Toughness characterizes the resistance to the propagation of flaws.

The knowledge of the rupture strength and the toughness allows the calculation of the critical flaw size $\left(a_{C}\right)$ (Evans and Tappin 1972). In the case of brittle material, a crack nucleates at a pre-existing flaw and propagates catastrophically, leading to a fast brittle fracture. The pore could be considered as flaw or as an integral part of flaw responsible for the failure. If such an assumption is valid, the critical flaw size should depend on the porosity and pore size change.

Aerogels are brittle in tension, but several works (Scherer 1995; Pirard et al. 1995; Duffours et al. 1995) have shown that if the aerogel is subjected to a compression load, after the stress is released an irreversible strain is observed (plastic behavior). This plastic shrinkage is strongly dependent on the structural features of the porous solid. Owing to the plastic shrinkage, the material shrinks progressively by pore collapse, and volume shrinkage higher than $50 \%$ can be observed. In summary, when it is submitted to tension stress, the mechanical behavior of silica aerogel is that of a brittle solid and when submitted to compression it behaves like a plastic material. Obviously, the elastic, brittle, and plastic properties are strongly dependent on the bulk density (pore volume) of the aerogels (Woignier et al. 2015).

It is clear that these peculiar features: poor load bearing fraction of solid, high porosity, and brittleness are important drawbacks to aerogels applications. Aerogels have poor mechanical resistance and the rupture is poorly predictable. A need arises to synthesize aerogels whose microstructural parameters can be easily adjusted, exploring the effect of various parameters on the fracture and plastic behavior. The aim of this chapter is to describe new kind of silica aerogels, the nanocomposites aerogels, presenting improved mechanical properties in terms of mechanical resistance and rigidity but also in terms of the control of the flaw size and strength distribution. We will adjust the mechanical properties of aerogels by the addition of silica particles (aerosil OX200). It must be noted that this kind of nanocomposites gels has been previously used as host matrix to confine nuclear wastes (Reynes et al. 2001; Aravind et al. 2007; 2008). We will follow the evolution of the textural and structural features (bulk density, specific surface area, fractal dimension, and aggregates size) versus the silica particles addition. In the same time, we will measure the mean mechanical properties (elastic modulus and rupture strength), the brittleness (toughness, critical flaw size, initiating fracture energy), the statistical failure features (strength distribution and Weibull modulus) but also the plastic densification (compression) for a set of nanocomposite aerogels. Finally, we will discuss the effect of structural features on the brittle and plastic behavior. 


\section{Textural Properties of Nanocomposites Aerogels}

It is obvious that the elastic and mechanical properties should be strongly dependent on the load bearing fraction of solid and thus on textural properties like the pore volume (i.e., the bulk density) (Gibson and Ashby 1988; Rice 1998). In the literature, it has been shown that the addition of fumed silica such as "aerosil" in the gelling solution will increase the bulk density and favors the formation of large pores (Toki et al. 1988; Marlière et al. 2001). Fumed silica (aerosil OX200 from Degussa) was added to the hydrolyzed solution of tetraethylortosilicate (TEOS), and the aerosil weight percentage (reported to the total silica weight) ranges between $0 \%$ and $70 \%$. Composites alcogels are transformed into aerogels by supercritical drying (Woignier 2011). Bulk density was determined measuring the samples weight and dimensions. Pore volume has been calculated using the samples bulk and skeletal silica density $\left(2 \mathrm{~g} \mathrm{~cm}^{-3}\right)$.

The literature explains that some monolithic aerogels can cracks several months later because of subcritical flaw propagation (Etienne et al. 1995; Despetis et al. 2001). This behavior being the results of internal stresses and progressive rupture of siloxane bonds by the action of water at the tip of the flaws. This process is well known in silica glass (Evans 1974; Michalske and Freiman 1983). The internal stresses are the results of shrinkage occurring during the supercritical drying (Woignier et al. 1994), and data suggest that the supercritical drying affects the microstructure of the samples (Pauthe et al. 1991). To explain the shrinkage of the materials, we can invoke syneresis processes occurring in the autoclave. The formation of siloxane bonds by condensation reactions of silanol groups increases the connectivity but would also impose stresses on the alcogel network. Moreover, the mechanism of dissolution-precipitation, driven by difference in solubility, leads to the growth of the necks between particles (Iler 1979). These processes are accelerated by the high temperature and pressure (Alaoui et al. 2000). To favor the synthesis of aerogels without internal stresses, it is necessary to minimize this shrinkage. Since shrinkage was observed to be isotropic it was determined simply by measuring the length of the gel samples with a cathetometer. The Fig. 1 shows that shrinkage could be as high as $60 \mathrm{vol} \%$, but the addition of silica particles decreases the magnitude close to 3 vol.\%. The addition of silica particles hinders the syneresis effect because the large silica particles oppose to a restructuring. So silica additions limit the shrinkage and decrease the associated internal stresses.

The Fig. 1 also shows the bulk density evolution versus particles addition (Woignier 2011). Bulk density was determined measuring the samples weight and dimensions. Data are the results of the mass increase (addition of silica particles) and volume shrinkage. At low aerosil concentration, the net result is a quite constant bulk density, and for higher aerosil concentration the mass addition clearly increases the bulk density.

The Fig. 2 shows the evolution of the specific surface area with the increase of the silica particles addition. Specific surface area (S) is measured by nitrogen adsorption-desorption experiments (BET analysis). Two conclusions can be drawn 
Fig. 1 Evolution of the volume shrinkage (dashes) and bulk density (circles) versus particles addition in the gelling solution

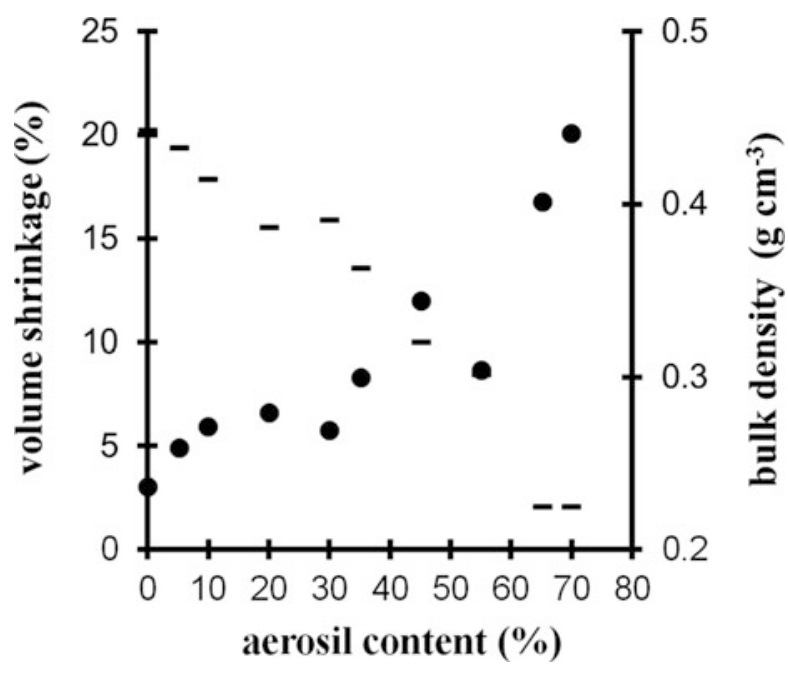

Fig. 2 Evolution of the specific surface (dashes) are and aggregate size (circles) versus particles addition in the gelling solution

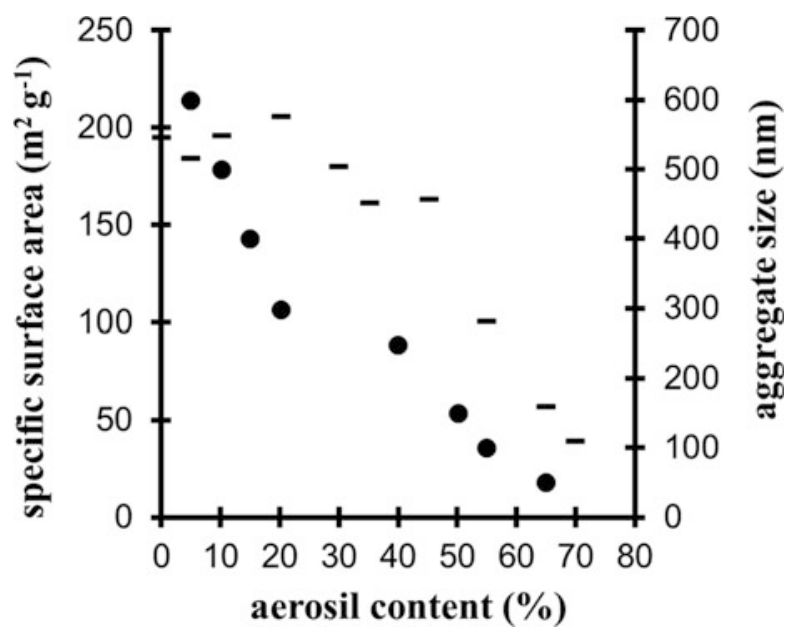

from the data. Specific surface area is almost constant in the range $0-40 \%$ of added silica particles. It means that the microporosity and mesoporosity are not affected because high specific surface area is generally the signature of small size pores. However, for higher silica addition, $\mathrm{S}$ decreases rapidly indicating an important structural modification (Marlière et al. 2001). From these results, we can make the assumptions that the gel aggregation and the aerogel structure are affected by the addition of high concentration of silica particles. In the literature (Toki et al. 1988), we noticed an increase in pore diameter with aerosil concentration and the higher the aerosil content, the sharper the pore size distribution. Therefore, we consider a nanocomposite aerogel of higher concentration (and bulk density) as being more homogeneous and with less disorder (narrow pore size distribution). 
Fig. 3 Typical scattered intensity I (q) versus q (wave vector) of nanocomposite aerogel

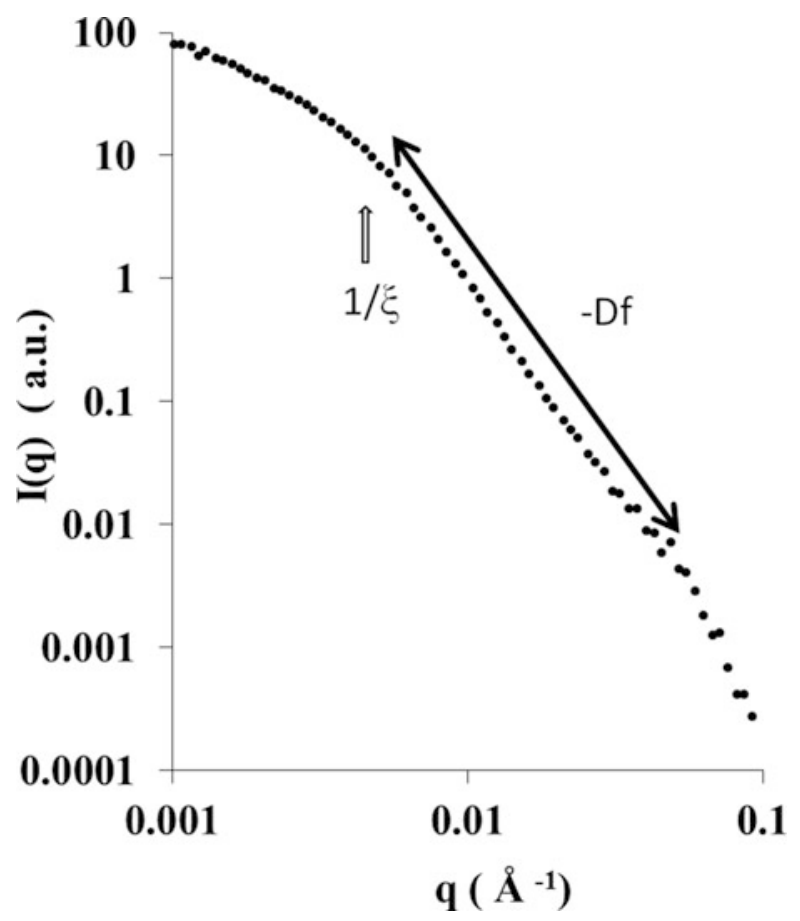

To have a better description of the porous structure, we will use scattering techniques like SAXS and characterize the fractal features of the composite aerogels. SAXS spectra have been obtained at ESRF, the European Synchrotron Radiation Facilities. Experiments were done at a wavelength of $1 \AA$. The smallest scattering wave vector for which relevant data were measured was about $1.10^{-4} \AA^{-1}$. For clarity, the curves are shifted and the intensity is plotted in arbitrary units. Typical SAXS curves are reported in the Fig. 3. The scattered Intensity I(q), and (q), the wave vector, are plotted on a $\log -\log$ scale. SAXS experiments generally give information on three main features of the aerogel structure: the mean size of the aggregates $(\xi)$ which are connected to form the network, the mean size of the primary particles which stick together to build the aggregate and the fractal dimension $D_{f}$ which expresses the aggregates compactness. The position of the low q crossover is related to the inverse of the aggregate size $\xi$ (open arrow in Fig. 3); the linear part has a slope equal to $-D_{f}$. To analyze the data, the SAXS curves have been fitted with a relation previously used (Marlière et al. 2001), which allows to calculate the aggregate size $\xi$ and the fractal dimension $D_{f}$.

In the literature, different works have shown and characterized the fractal structure of classical silica aerogels (Emmerling and Fricke 1997; Schaeffer and Keefer 1986; Woignier 1990; Courtens et al. 1987). A fractal structure is characterized by pores at different sizes. The structure of classical aerogels is fractal in the range $1-10 \mathrm{~nm}$, with a high fractal dimension in the range $1.8-2.3$ depending on catalysts conditions. This high $D_{f}$ has been interpreted as the 
signature of a cluster-cluster aggregation process followed by a restructuring. The important syneresis effect observed on classical aerogels is likely responsible for the restructuring.

From the SAXS curves obtained on the nanocomposites we have measured the $\xi$ values (Woignier 2011) and the Fig. 2 shows the variations of $\xi$ as the aerosil concentration increases. As observed, the aggregates size decreases when the aerosil content increases, which means that the fractal range shrinks. The fractal dimension is close to 1.6 in agreement with the Diffusion Limited Cluster Aggregation (DLCA) model (Ma et al. 2001) and does not evolve as a function of the aerosil content (Marlière et al. 2001). Results show that for high aerosil concentration, the fractal structure progressively disappears. Obviously, the number of aggregates increases with the aerosil concentration and the growth of the each aggregate is limited by the neighboring ones. This process gives place to a structure more homogeneous, with a narrow pore size distribution (Toki et al. 1988). The low fractal dimension 1.6 measured on nanocomposites aerogels is in a close agreement with the absence of fractal aggregate restructuring.

\section{Mechanical Properties of Nanocomposites Aerogels}

In ceramics and composites technology, it is generally admitted that inclusion of particles or fibers in the material could change the pore structure and improve the mechanical properties. We have seen that it is possible to adjust the bulk density by the addition of silica powder in the monomer solution, just before gelation. The Fig. 4 shows the evolution of the elastic properties (Young's and longitudinal modulus) of the nanocomposite aerogels as a function of the aerosil content. The elastic Young' modulus, $E$, was measured by a 3-point bending technique using an

Fig. 4 Evolution of the Young (diamonds) and longitudinal moduli (circles) of the nanocomposite aerogels versus the silica particles addition

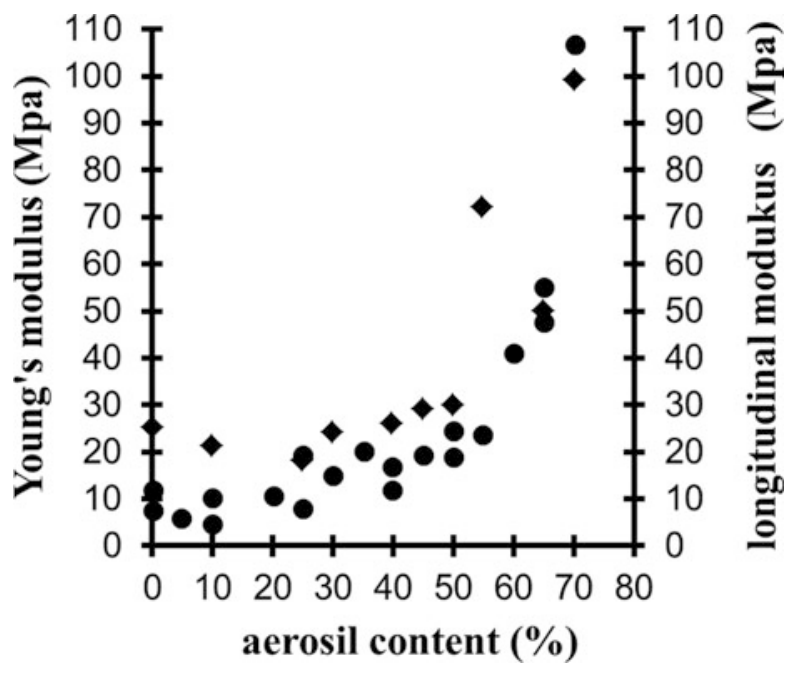


Instron testing 1196 machine. The crosshead speed may be varied from $10 \mu \mathrm{m} / \mathrm{min}$ to $100 \mathrm{~mm} / \mathrm{min}$. The load is measured by a balance able to record forces up to $4 \mathrm{~N}$ with an accuracy of $10 \mu \mathrm{N}$. The Young's modulus $E$ is obtained using the relationships:

$$
E=\frac{4 T L^{3}}{3 \pi D^{4} y}
$$

where $D$ is the sample diameter, $T$ the applied load inducing a deformation $y . L$, the span, is $60 \mathrm{~mm}$.

The longitudinal modulus, $H$, of the samples is calculated from the sound velocity of longitudinal waves $V$ and the bulk density $\rho$. The setup consists of two identical transducers (emitter and receiver). The measurements were made with a set of transducers (Panasonic V101, $500 \mathrm{kHz}$ ).

$$
H=\rho V^{2}
$$

In a previous study (Marlière et al. 2001), we have seen that the nanocomposite structure is made of two imbricate networks: the polymeric and the silica particles networks. Consequently, the mechanical properties of the nanocomposite aerogels should depend on the relative influence of the two structures. As expected, the aerosil addition increases the elastic properties but not linearly, mechanical properties show a clear different behavior in the aerosil range $0-40 \%$ compared to the range 40-70\%. The mechanical features measured on the sample set are quite constant between $0 \%$ and $40 \%$. For this concentration range, the aerosil particles may be assumed as playing no role in establishing the connectivity, and they do not participate in load transfer. These nanocomposite aerogels show an elastic behavior analogous to that of the polymeric classical aerogel; this result is the direct consequence of the nonevolution of the bulk density (Fig. 1). For this concentration range, the aerosil particles are not connected between them and the elastic waves propagate preferentially through the polymeric structure. For concentrations higher than $40 \%$, the addition of silica particles increases the bulk density and consequently the load bearing fraction of solid. The mechanical properties rapidly increase and silica particles stiffen the structure by a factor of 8 . Above "the percolation threshold," $40 \%$, the aerosil network participates to the load transfer.

Figure 5 shows the evolution of the mechanical strength $\sigma$ of the nanocomposite aerogels versus the silica particles addition. The mechanical strength $\sigma$ of samples is obtained using the relationships:

$$
\sigma=\frac{8 T m L}{\pi D^{3}}
$$

where $T m$ is the maximum load inducing the fracture. In the same way than elastic properties, the mechanical resistance rapidly increases with aerosil concentration above the percolation threshold $(40 \%)$. The aerosil particles strengthen the structure by a factor 4 . 
Fig. 5 Evolution of the mechanical strength (diamonds) and toughness (circles) of the nanocomposite aerogels versus the silica particles addition

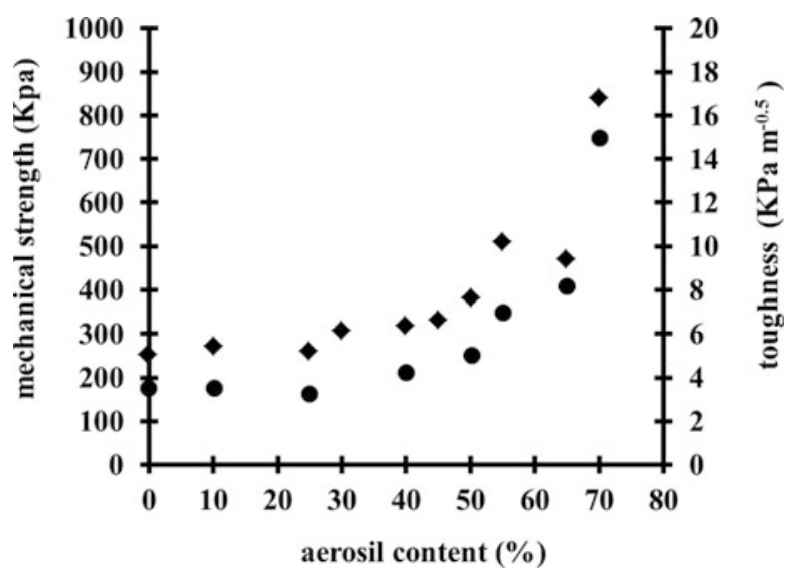

In conclusion, the addition of high concentration of silica particles will improve the macroscopic mechanical properties $E, H$, and $\sigma$. However, the increase of the solid fraction will not enhance linearly the mean mechanical properties because of the complicated structure of the composite aerogel. The $E, H$, and $\sigma$ values of composites aerogel are higher than for neutral aerogels having the same bulk density; we can conclude that the aerosil addition leads to an increase of the connectivity or of the size of the necks between particles.

\section{Brittle Behavior of Nanocomposites Aerogels}

As explained in the introduction, the characterization of $\sigma, H$, and $E$ is not enough to have a true description of the whole mechanical behavior of aerogels especially because of their brittleness and poorly predictable failure. The application of the linear elastic fracture mechanics on gels was questionable because it is necessary to justify that the material has an elastic behavior but also can be treated as a continuum. Scherer (1992) and Phalippou et al. (1989) have previously shown that it seems reasonable to apply fracture mechanics because the elastic region near the tip of the crack is larger than the plastic deformation at the crack tip.

\section{Toughness}

Because gels behave as brittle materials, the mechanical strength $(\sigma)$ is strongly defendant on the presence of flaws, which act as stress concentrators. A relevant feature of brittle materials is their toughness $\left(K_{I C}\right)$ which characterizes the ability of the material to resist to the propagation of flaws. Failure is assumed as the result of the stress concentration at the flaw tip in gels (Zarzycki 1988; Scherer 1992; Alaoui et al. 2000). 
In this study, the toughness is measured by the Single Edge Notched Beam (SENB) technique previously described (Alaoui et al. 2000). The corresponding relationship is:

$$
K_{I C}=\frac{3 T m L}{2 w^{3}} Y \sqrt{a}
$$

where $w$ is the sample width, $a$ the dimension of the notch done with a saw of $50 \mu \mathrm{m}$ thickness, and $Y$ a polynomial function (Alaoui et al. 2000).

In Fig. 5, the toughness of composites increases with the aerosil content and confirms the result previously measured on $E$ and $\sigma$. The toughening of the sets of materials is directly related to the decrease of the pore volume. The reported values are two decades lower than those measured on dense silica glasses (700-1500 KPa. $\mathrm{m}^{-0.5}$ ) (Wiederhorn 1974; Phalippou et al. 1989).

\section{Critical Flaw Size and Fracture Energy}

The knowledge of $E, K_{I C}$, and $\sigma$ allows one to calculate the critical flaw size, $a_{c}$ (Evans and Tappin 1972; Phalippou et al. 1989) and the initiating facture energy $\Gamma$.

$$
\begin{gathered}
a_{C}=1 / 1.21 \pi\left[\frac{K_{I C}}{\sigma}\right]^{2} \\
\Gamma=\left[K_{I C}\right]^{2}\left[1-\nu^{2}\right] / 2 E
\end{gathered}
$$

where $\nu$, the Poisson ratio, is equal to 0.2 . The $a_{c}$ and $\Gamma$ evolutions versus the aerosil concentration for the nanocomposite aerogels are reported on Fig. 6.

The values of the initiating fracture energy are lower than that measured on silica glass $\left(\sim 5 \mathrm{Nm}^{-1}\right)$. The range of $\Gamma$ is close to the data for classical aerogels (0.3-0.1 Nm $\mathrm{Nm}^{-1}$ ); however, contrary to the classical aerogel (Phalippou et al. 1989), $\Gamma$ increases with the bulk density (aerosil content increase) for the nanocomposite aerogels. This behavior is expected with respect to the porosity evolution (Rice 1998; Vandeperre et al. 2004; Li et al. 2009).

In porous ceramics, fracture toughness and especially fracture energy commonly show less porosity dependence than strength and Young's modulus. In some cases, little increase or possibly a temporary decrease in fracture energy is seen with decreasing porosity in contrast to continuous increases for strength and Young's modulus. Experiments have been carried out where cracks have been grown in porous poly methyl methacrylate (Vandeperre et al. 2004). Their results show that for low porosity range the applied force required to grow the crack between two pores can be greater than that required to grow the crack in the pore-free material. This increase in applied force is associated with the crack front becoming curved in the vicinity of the pore. 
Fig. 6 Evolution of fracture energy (dashes) and critical flaw size (circles) of the nanocomposite aerogels versus the silica particles addition

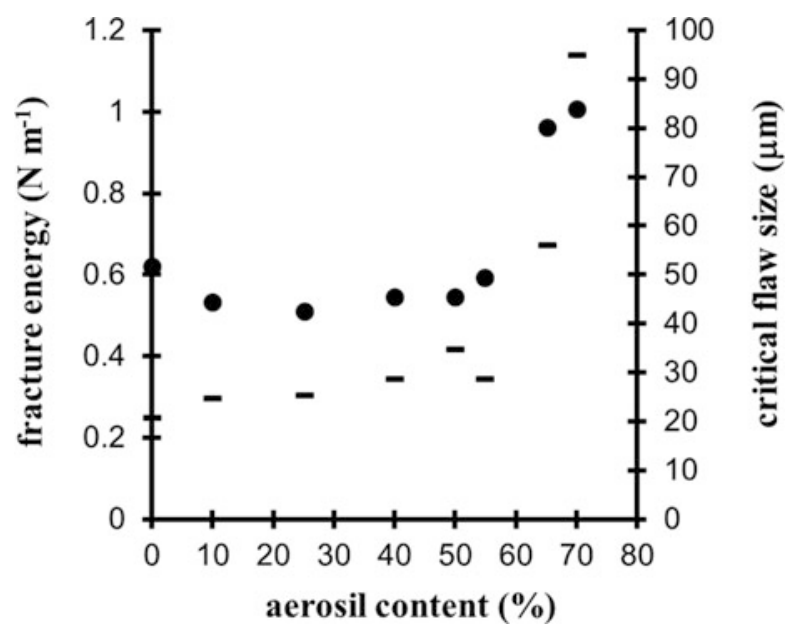

The unexpected $\Gamma$ decrease versus the density increase for classical aerogels is attributed to their high specific surface area and roughness (Phalippou et al. 1989).

As suggested in the literature (Alaoui et al. 2000), a correlation could exist between $a_{C}$ and the evolution of the pore size. The results in Fig. 6 confirm this tendency: the literature shows that the macroporous volume is progressively enhanced (Toki et al. 1988), and Fig. 6 shows that $a_{c}$ increases, with the aerosil concentration. However, we note that the $a_{C}$ values are much larger $(50-100 \mu \mathrm{m})$ than the pore size $(500-1000 \mathrm{~nm})$. The scale of critical crack extends on a large number of pores, and consequently the critical flaws might be created during the test. We can suppose that the failure occurs by progressive breaking bonds following the minimum solid area and associating the large macropores. The macropores link into a macroscopic flaw and fracture occurs when the size of the flaw becomes critical. In conclusion, the $a_{c}$ values suggest that the flaw size should be affected by the elaboration parameters. If this assumption is valid, the flaw size distribution and the Weibull modulus (m), which characterizes the strength distribution (and consequently the flaw size distribution), has every chance to change because of the aerosil addition.

\section{Statistical Analysis of the Rupture Strength (Weibull Analysis)}

For brittle materials, the broad scattering of the mechanical strength values is attributed to statistical nature of flaws. The sample strength distribution is usually analyzed using Weibull's statistical analysis. For samples of identical dimensions, for which the effective volume is assumed constant, the failure probability is given by the relationship (Sullivan and Lauzon 1986; Duffours 1995). 


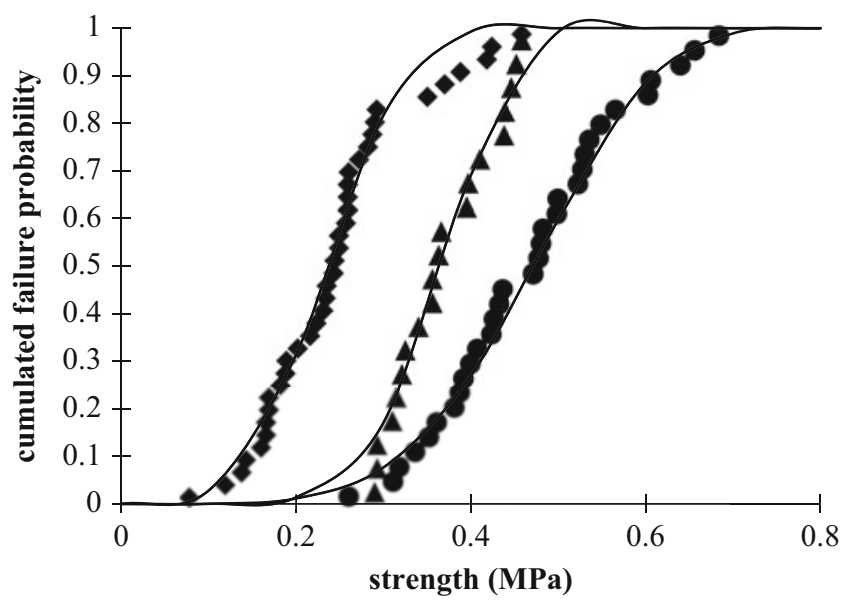

Fig. 7 Experimental (discrete data) and calculated (continuous line) cumulated failure probability for aerogels with increasing aerosil concentration: $0 \%$ (diamonds); $40 \%$ (triangles); and $65 \%$ (circle)

$$
P(\sigma)=1-\exp \left[-\left(\frac{\sigma}{\sigma_{o}}\right)^{m}\right]=P_{j}
$$

The cumulative failure probability, $P_{j}$, has been calculated using the estimator (Sullivan and Lauzon 1986): $P_{j}=\frac{j-0.5}{N}$, where $j$ is the order of the sample and $N$ (more than 40) is the total number of samples. The Weibull's modulus, $m$, is a shape factor which characterizes the breadth of the strength distribution. Small $m$ value is characteristic of a wide distribution of the strength. $\sigma_{\mathbf{0}}$ is a scale parameter characterizing the mean rupture strength.

Previous study has shown that $m$ is generally low for classical aerogel (Duffours et al. 1995). The critical flaw sizes are highly dispersed because of a large pore size distribution. To confirm a possible effect of the pore size distribution on the $m$ values, we have measured the $m$ on the set of nanocomposite aerogels. As explained above, the addition of silica particles in the solution before gelling strongly affects the pore size distribution and the structure. The pore microstructure of the nanocomposites aerogels evolves from a large pore size distribution with a fractal structure towards a more homogeneous porous material with a narrow pore size distribution, when the aerosil content increases.

Figure 7 shows the large scattering in the data due to the statistical nature of the mechanical strengths. On this figure is reported the experimental and calculated cumulated failure probability using the Weibull's statistical analysis. From these data, we have calculated the failure probability density (Fig. 8) (Duffours et al. 1995) and the $m$ and $\sigma_{0}$ value for the different nanocomposite aerogels (Fig. 9).

Figure 9 shows the results of the Weibull's analysis, and as expected, for the low aerosil concentration the $m$ value is low $(\sim 3-4)$. It corresponds to a large strength and 
Fig. 8 calculated failure probability density function for aerogels with increasing aerosil concentration: $0 \%$ (full line); $40 \%$ (dashed line), $65 \%$ (dotted line)

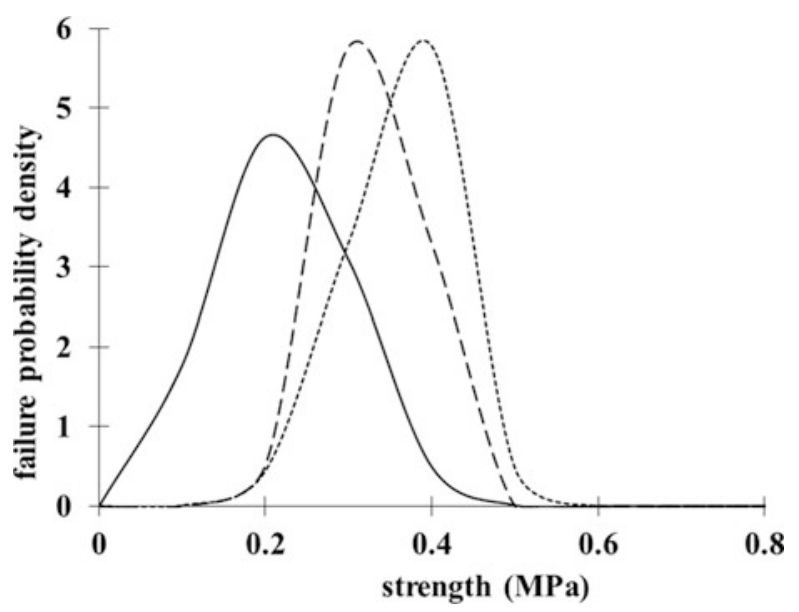

Fig. 9 Weibull parameters $m$ and $\sigma_{\mathrm{o}}$ value versus the aerosil concentration

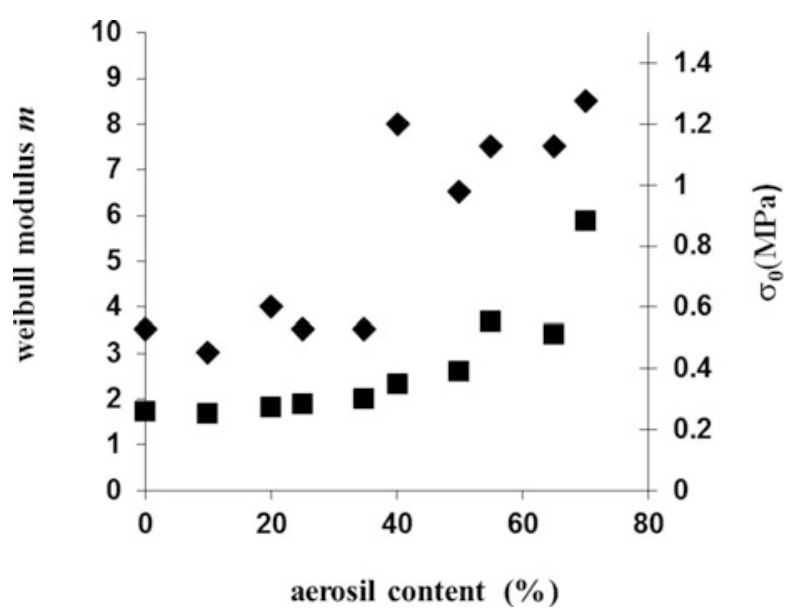

flaw size distribution. When the aerosil concentration is higher than $40 \%$, the $m$ value is more than twice $(\sim 7-8)$. This result shows the correlation between the pore size distribution and the flaw size distribution and comfort the idea that the failure would occur by progressive collapsing of a large number of pores. We also note that the $\sigma_{0}$ values are quite close to the data of the mechanical strength in Fig. 5.

\section{Plastic Densification in Silica Aerogels}

In the preceding section, silica gels are described as purely elastic materials and the stress-strain relation evolve like for a common elastic material toward a catastrophic fracture. However, previous works (Pirard et al. 1995; Scherer et al. 1995; Duffours 1995) have shown that if a classical aerogel is subjected to a high compression load, 
Fig. 10 Relative volume shrinkage versus pressure for a nanocomposite aerogel ( full line) and oxidized nanocomposite aerogel (dotted line)

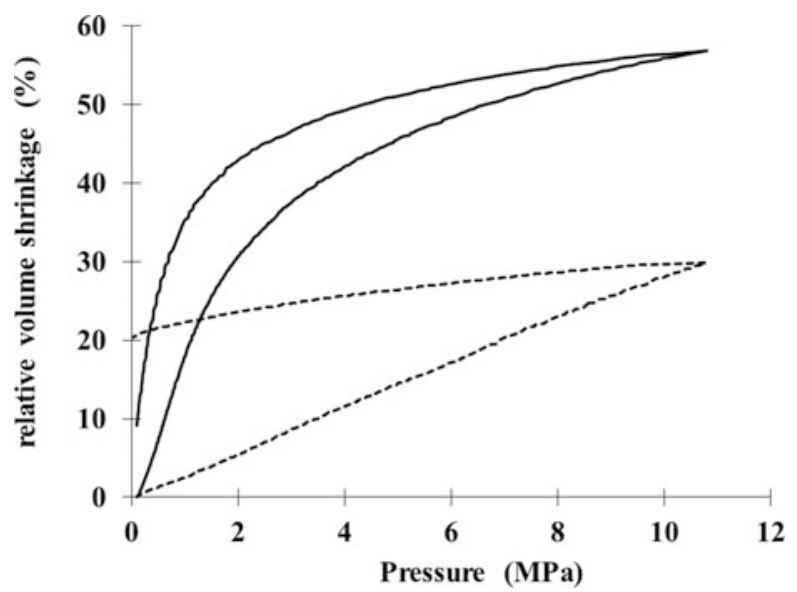

the strain is no longer proportional to the stress and aerogel networks can deform irreversibly. This phenomenon has been discovered and studied using a $\mathrm{Hg}$ porosimeter which provides the shrinkage amplitude (Pirard et al. 1995). In such experiments, as mercury do not penetrate the aerogel small pores, the aerogel is isostatically compressed.

Isostatic compression experiments are done using a $\mathrm{Hg}$ porosimeter (Carlo Erba Porosimeter 2000$)$ on outgassed monolithic aerogel $\left(\approx 1 \mathrm{~cm}^{3}\right)$. Hg pressure can be varied from 0.1 to $200 \mathrm{MPa}$. The aerogel is compressed up to a selected pressure value. After depressurization, the irreversible volume shrinkage is precisely measured from the mercury level using a cathetometer, which allows calculation of the bulk density (Duffours et al. 1995).

Figure 10 shows the response behavior of two different nanocomposite aerogels during a compression run. When the pressure applied is higher than the yield strength, the behavior is no longer elastic and the volume strain is irreversible. After the complete pressure release, the residual volume strain characterizes its plastic deformation (10\% in Fig. 10). Thus, as a function of the pressure applied during the run, the sample bulk density increases. The yield stress and the magnitude of the plastic shrinkage are strongly dependent on the structural features of the silica aerogel (Duffours et al. 1995). Owing to the plastic shrinkage, the material shrinks progressively by pore collapse. If several cycles of pressurization are applied with increasing pressure, the aerogels shrink with each cycles and volume shrinkage higher than $50 \%$ have been measured.

This behavior could be compared to polymeric foams (Deschanel et al. 2009). The compressive behavior of polymeric foams has been widely studied: three phases of deformation are commonly observed. The first phase is linear elastic response (due to cellular wall bending), where stress increases linearly with deformation and the strain is recoverable. The second phase is characterized by continued deformation at relatively constant stress (plateau). The final phase of deformation is densification in which the stress rises steeply and where the foam begins to respond as a 
Fig. 11 Bulk density versus pressure for classical nanocomposite aerogels with increasing aerosil concentration: $0 \%$ (circles); $50 \%$ (squares) and 70\% (diamonds)

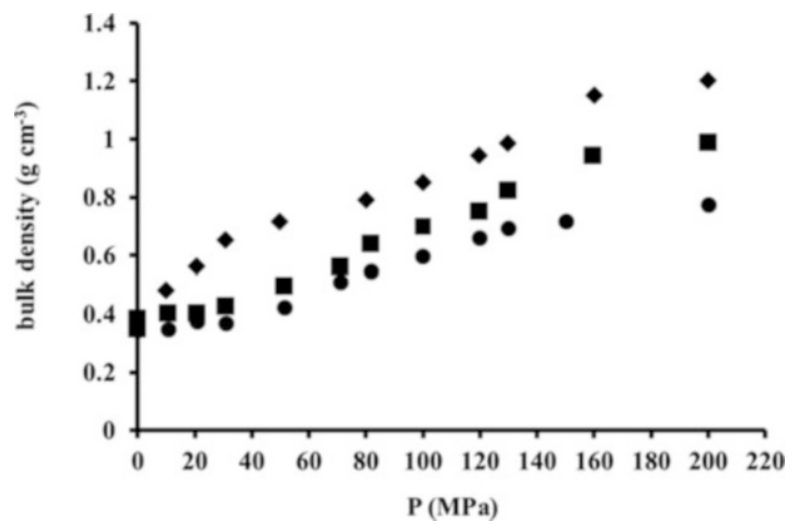

compacted solid. The Fig. 10 shows that the curves for aerogels do not present a plateau. The curves show also clearly that the oxidation treatment favors the plastic volume shrinkage (around $20 \%$ in Fig. 10). After oxidation the structural organic groups $\mathrm{SiOR}$ are replaced $\mathrm{SiOH}$; the aggregates are chemically active (Woignier 1990) and they may react between them if silanol groups are close enough to condense, forming a new siloxane bonds (Duffours et al. 1995). This connectivity increase leads to the freezing of the strained structure.

The main parameters of this densification by compression are the compliance of the material, the bulk density, and the silanol content, but the macroporous volume is also important parameters. The rearrangement of the aggregates would be favored by the presence of large pores in the network, allowing the aggregates to move and leading to the nanocomposite aerogel densification.

Figure 11 shows the final bulk density (after compression) versus the pressure applied for nanocomposites samples with different aerosil concentration $(0 \%, 55 \%$ and $70 \%$ ). The nanocomposite aerogel (55 and 70 aerosil \%) have a macroporous volume larger than the classical sample ( $0 \%$ ) (Toki et al. 1988; Marlière et al. 2001). This figure shows the strong effect of the macropores on the plastic shrinkage of nanocomposite aerogels. The final bulk density of nanocomposite aerogels $(50 \%$ and $70 \%)$ is twice that of the classical aerogel $(0 \%)$ over the range of pressure studied. Because of larger macropores volume and a more homogenous pore size distribution, the aggregates can fill the macropores more easily. With this compaction process, we could imagine to fully densify the porous structure like by sintering. It was demonstrated that aerogels could be fully densified (bulk density $2.2 \mathrm{~g} . \mathrm{cm}^{-3}$ ) by viscous flow sintering in the temperature range $1000-1200{ }^{\circ} \mathrm{C}$ (Woignier 1990). The extrapolation of the nanocomposite aerogel compression curves leads to the conclusion that fully dense silica glass could be achieved in the pressure range close to $500 \mathrm{MPa}$.

However, Duffours et al. (1995)) shows that the higher the compression pressure, the higher the rigidity of the compacted material leading to a more difficult supplementary compaction. Because the solid is not viscous, such a restructuring induces important strain and local decohesion in the network. To allow the moving of the 
aggregates, a part of the links at the boundaries between aggregates is broken which could lead to the formation of flaws. For these brittle materials, plastic yielding and brittle crushing should lead to the material fracture, before a complete densification.

\section{Conclusions}

As explained in the introduction, aerogel has specific properties because of its very large porosity (up to $99 \%$ ). The possibility to fill and/or to sinter the porous structure is another way to enlarge the interest and applications of aerogels, but the low and poorly predictable mechanical properties is clearly a problem.

Results on the mechanical properties of nanocomposites aerogels show that the elastic moduli, the mechanical strength, the toughness, and the fracture energy increase with the aerosil concentration. The bulk density of the nanocomposite aerogels is the main parameter which defines the elastic and brittle features, but others parameters like pore size distribution is also significant to describe and understand the brittle behavior.

Toughness measurements have shown that the flaw size responsible for the fracture seems to be related to the size of the largest pores. The results show that the critical flaw size $a_{c}$ would be in the range $10-100 \mu \mathrm{m}$ close to the size of the Griffith flaws characteristics of usual glasses. Failure occurs by progressive breaking bonds collapsing a large number of pores and fracture occurs when the size of the flaw becomes critical.

The literature (Etienne et al. 1995; Despetis et al. 2001) describes how slow crack growth occurs by a stress corrosion effect, and after several months monolithic aerogels have cracked only because of internal stresses. The stress corrosion effect will limit their technological applications if the materials are permanently under stress. In the case of nanocomposite aerogels, the absence of internal stresses suggests that nanocomposite aerogels are certainly less sensible to this mechanical fatigue.

Besides the brittle elastic behavior, under a compression load the porous network can be irreversibly transformed. This plastic behavior is also strongly affected by the macropores. With respect to their texture, nanocomposites aerogels exhibit a larger densification than classical aerogels. This new way to eliminate the large pore volume of aerogels could be interesting in the case of the synthesis of multiphase materials where silica will be associated to compounds sensitive to the temperature. By this "sintering at room temperature," chemical dyes could be introduced and trapped in the porous network after compression runs. However, because of a progressive plastic hardening the densified structure become more rigid with the compression runs and the full densification should not be achieved before the crushing of the material.

Thanks to their enhanced mechanical features, their more homogeneous and permeable porous structure the nanocomposite aerogels have been successfully used as a porous and sinterizable host matrix for nuclear wastes and can be precursors for the synthesis of glass ceramics, doped glasses, and composites (Aravind et al. 2008; Reynes et al. 2001; Woignier 2005). 


\section{References}

Aegerter MA, Leventis N, Koebel MM. Aerogels handbook. New York: Springer; 2011.

Alaoui A, Woignier T, Perno F, Phalippou J. Stress intensity factors in silica alcogels and aerogels in aerogels. J Non-Cryst Solids. 2000;265:29-36.

Aravind PR, Sithara L, Mukundan P, Krishna PP, Warrier KGK. Silica alcogels for possible nuclear wastes confinement- a simulated study. Mater Sci Lett. 2007;61:2398-401.

Aravind PR, Shajesh P, Mukundan P, Krishna PP, Warrier KGK. Non- supercritically dried silicasilica composites aerogel and its possible application for confining nuclear wastes. J Sol-Gel Sci Technol. 2008;46:146-51.

Brinker J, Scherer S. Sol-gel science. New York: Academic; 1990.

Courtens E, Pelous J, Phalippou J, Vacher R, Woignier T. Brillouin-scattering measurements of phonon-fracton crossover in silica aerogels. Phys Rev Lett. 1987;58:128-31.

Despetis F, Calas S, Etienne P, Phalippou J. Effect of oxidation treatment on the crack propagation rate of aerogels. J Non-Cryst Solids. 2001;285:251-5.

Deschanel S, Vanel L, Godin N, Maire E, Vigier G, Ciliberto S. Mechanical response and fracture dynamics of polymeric foams. J Phys D Appl Phys. 2009;42:214001. https://doi.org/10.1088/ 0022-3727/42/21/.

Duffours L, Woignier T, Phalippou J. Plasticity of aerogels under isostatic pressure. J Non-Cryst Solids. 1995;186:321-7.

Dumas J, Quinson JF, Serughetti J. Hierarchy of pores and mechanical behavior of wet silica gels. J Non-Cryst Solids. 1990;125:244-9.

Elmer TH. Porous and reconstructed glasses. In: Engineered materials handbook, Ceramics and glasses, vol. 4. Materials Park: ASM international; 1992. p. 427-32.

Emmerling A, Fricke J. Scaling properties and structure of aerogels. J Sol-gel Sci Tech. 1997;8:781-8.

Etienne P, Phalippou J, Woignier T, Despetis F, Alaoui A. Slow crack growth in aerogels. J Non-Cryst Solids. 1995;188:19-26.

Evans AG, Tappin G. Effects of microstructure on the stress propagate inherent flaws. Proc $\mathrm{Br}$ Ceram Soc. 1972;23:275-96.

Evans AG. Slow crack in brittle materials under dynamic loading conditions. Int $\mathrm{J}$ Fract. 1974;10:251-61.

Fricke J. Aerogels and their applications: aerogels and their applications aerogels and their applications. J Non-Cryst Solids. 1992;147-148:356-62.

Gibson LJ, Ashby MF. Cellular solids structure and properties. Oxford, UK: Pergamon Press; 1988.

Griffith AA. The phenomenom of rupture and flow in solids Philos. TransR Soc London Ser A. 1920;221:168-98.

Iler RK. The chemistry of silica. New York: Wiley; 1979.

Li H, Lin Y, Tsui TY, Vlassak JJ. The effect of porogen loading on the stiffness and fracture energy of brittle organosilicates. J Mat Res. 2009;24:107-16.

Ma HS, Prevost JH, Jullien R, Scherer GW. J Non-Cryst Solids. 2001;285:216-21.

Marlière C, Woignier T, Dieudonné P, Primera J, Lamy M, Phalippou J. Two fractal structure in aerogel. J Non-Cryst Solids. 2001;285:175-81.

Michalske TA, Freiman SW. A molecular mechanism for stress corrosion in vitreous silica. J Amer Ceram Soc. 1983;66(4):284-8.

Phalippou J, Woignier T, Rogier R. Fracture toughness of silica aerogels. Rev Phys Appl. 1989;24: C4-191-6.

Pauthe M, Quinson JF, Hdach H, Woignier T, Phalippou J, Scherer GW. Autoclave treatment effect on silica alcogel texture. J Non-Cryst Solids. 1991;130:1-7.

Pernot F, Baldet JF, Bonnel J, Zarzycki J, Rabischong P. Development of phosphate glass-ceramics for bone implants. Ceram Int. 1983;9(4):127-31.

Pirard R, Blacher S, Brouers F, Pirard JP. Interpretation of mercury porosimetry applied to aerogels. J Mat Res. 1995;10(8):2114-9. 
Reynes J, Woignier T, Phalippou J. Permeability measurements in composites aerogels: application to nuclear waste storage. J Non-Cryst Solids. 2001;285:323-7.

Rice RW. Porosity of ceramics properties and applications. New York: Marcel Dekker; 1998.

Schaeffer DW, Keefer KD. Structure of random porous materials: silica aerogel. Phys Rev Lett. 1986;56:2199-202.

Scherer GW, Smith DM, Qiu X, Anderson JM. Compression of aerogels. J Non-Cryst Solids. 1995;186:316-20.

Scherer G. Crack tip stress in gels. J Non-Cryst Solids. 1992;144:210-4.

Sullivan JD, Lauzon PH. Experimental probability estimators for Weibull plots. J Mat Sci Let. 1986;5:1245-7.

Toki M, Miyashita S, Takeuchi T, Kande S, Kochi A. A large-size silica glass produced by a new sol-gel process. J Non-Cryst Solids. 1988;100:479-82.

Vandeperre J, Wang J, Clegg WJ. Effects of porosity on the measured fracture energy of brittle materials. Philos Mag. 2004;84(34):3689-704.

Wiederhorn SM. Subcritical crack growth in ceramics. In: Fracture mechanics of ceramics. Bradt RC, Hasselman DPH, Lange FF, editors. Vol. 2. New York: Plenum Press; 1974. p. 613-46.

Woignier T, Phalippou J, Sempere R, Pelous J. Analysis of the elastic behavior of silica aerogels taken as a percolative system. J Phys France. 1988;49:289-93.

Woignier T, Phalippou J, Prassas M. Glasses from aerogels. J Mat Sci. 1990;25:3118-26.

Woignier T, Scherer GW, Alaoui A. Stress in aerogel during depressurization of autoclave : II Silica gels. J Sol-gel Sci Tech. 1994;3:141-50.

Woignier T, Primera J, Lamy M, Fehr C, Anglaret E, Sempéré R, Phalippou J. The use of gels as host matrices for chemical species. Different ways to control the permeability and the mechanical properties. Journal Non-Cryst solids. 2005;350:298-306.

Woignier T, Primera J. Mechanical behaviour of nano composites aerogels. J Sol-gel Sci Tech. 2011; 58:385-93.

Woignier T, Primera J, Alaoui A, Etienne P, Despestis F, Calas-Etienne S. Mechanical properties and brittle behavior of silica aerogels. Gels. 2015;1:256-75.

Zarzycki J. Critical stress intensity factors of wet gels. J Non-Cryst Solids. 1988;100:359-63. 